are so placed that any ship that can be reached satisfactorily by a shore station can in turn be picked up satisfactorily by one of the receivers associated with that shore transmitter.

Transmission from the shore station is at a frequency within the band 2,504-2,600 kc., while the shore receivers operate at between 2,108 and 2,208 kc. To call a shore station, the desired frequency is selected, the headset aboard ship is lifted, and the 'talk' switch on the handle is pressed. This turns on the ship's transmitter, and the radiated carrier causes a carrier-operated relay in one or more of the shore receivers to operate and light a lamp in front of an operator.

Two methods are available for calling ships. The more completely equipped vessels have a selective signalling system. The operator dials the ship as he would any shore subscriber, and a bell is rung aboard the vessel called. For ships not equipped for dial calling, the operator transmits a 1,000-cycle tone over the carrier from the shore transmitter, and then calls the ship by name or by its call letters. Such vessels have a loudspeaker associated with their radio receiver, and the tone serves as an attention signal. Besides completing calls between ship and shore, the terminal facilities also permit radio telephone conversations between ships through a shore station. The operating procedure is for the ship to call shore and ask for a connexion to some other ship. The shore operator then calls this other ship, and having reached it, plugs into a by-pass jack, which, through suitable contacts, rearranges the circuit. The output of the radio receiver is, connected to the input of the transmitter through a network, so that speech is re-transmitted at a frequency that can be detected by either vessel.

One of the innovations in the new terminal equipment is the ability to make contact with the emergency radio equipment of the telephone companies. This emergency equipment is designed to take the place of wire facilities that are temporarily out of service. The ability of the shore stations to communicate with these emergency sets is very helpful at times in establishing the original connexion, since then only one of the emergency sets is required, the shore station taking the place of the other. A second emergency equipment is put into use as soon as possible, however, and the operating frequency changed, so as not to tie up harbour equipment. The shore station radiates carrier continuously while handling calls with vessels, while for the emergency equipment the carrier must be under voice control. To make this possible, the technical operator is provided with a key that rearranges the circuit. The switching relay operates under control of the incoming carrier, to connect the shore circuit to the radio-receiver. Under these conditions, there is no speed input to the vogad and hence none to the amplifier-detector. As a result there is no current through the winding of the voice-holdover relay, and a circuit through its back contact disables the radio transmitter. When incoming speech ceases, the switching relay is released, thus connecting the shore circuit to the transmitter. Voice signals from the shore circuit result in a current in the output of the amplifier-detector that operates the voice-holdover relay, and causes the transmitter to radiate carrier. The same current also operates the echo-holdover relay, thus opening the circuit to the switching relay so that incoming speech cannot interfere with outgoing signals.

\section{CLIMATE AND ANIMAL DISEASE IN INDIA}

TN his presidential address read before the Section of Medical and Veterinary Sciences of the thirtieth Indian Science Congress held at Calcutta last January, Dr. F. C. Minett, director of the Imperial Veterinary Research Institute, Muktesar, United Provinces, discussed the influence of climate on the incidence of disease.

At the outset, Dr. Minett emphasized the value of the association of medical men and veterinarians in research, as is exemplified in the Indian Science Congress and in the Section of Comparative Medicine of the Royal Society of Medicine. While admitting that veterinary science has gained more than it hais given by contact with medicine, he dwelt on the enormous extent to which medical science has had to rely upon experiments on animals in connexion with elucidation and prevention. As regards the effect of climate and weather conditions on animal health and disease, Dr. Minett mentioned the influence of air temperature and humidity on the spread of such diseases as filariasis, malaria and plague. On the other hand, climate may not be the only environmental factor at work; other complex influences, such as naturally acquired immunity and conditions of crowding, may be still more important. Climatic factors might be neutralized by the occurrence of improved facilities for disinfection, as in the case of cholera. As the relation between weather effects and disease in man cannot always be determined by statistics, experiments on animals are needed, with results which may or may not confirm previous deductions.

Although a good deal is known of the effect of environmental factors, including climate, on human beings and small experimental animals, comparatively little is known with regard to domesticated animals like sheep and goats. In order to obtain more exact information, figures are being collected through provincial directors of veterinary services relating to the prevention of animal diseases during the monsoon period, just as has been done on the medical side with cholera, typhoid, etc. As regards the monsoon prevalence of disease, wet conditions are a sore trial to many animals in some tropical countries, even to such water-loving animals as buffaloes. The effect of rainfall on animals has recently been studied by artificial showers. Sheep inoculated intramuscularly with very small doses of spores of $\mathrm{Cl}$. chauvoei, the causal agent of blackwater in cattle and sheep, showed symptoms of the disease and died after exposure to a shower, while control sheep remained healthy. On the other hand, guinea pigs injected with the spores and then treated in an incubator at $40^{\circ} \mathrm{C}$. are more likely to escape the disease than controls. A similar effect has been produced in the case of anthrax.

Dr. Minett next dealt with the deterioration or degeneration of cattle, which it is hoped will be investigated by the Imperial Council of Agricultura] Research. Whether the deterioration is solely or mainly due to climate is not yet known; but if it is, it will have to be determined whether climate is exerting a direct effect on the animal physiology, or whether the effect is indirect and is more properly to be attributed to a hot atmosphere.

In conclusion, Dr. Minett referred to the control of disease in India, which is hindered by religious 
prejudices whereby the survival of useless animals and active dissemination of disease are permitted. Further, there is the undeveloped legislation for controlling animal diseases and the extensive movements of cattle, sheep and goats which are made annually for food to escape the monsoon. In spite, however, of shortage of staff and difficulties of communication, Dr. Minett considers that much success has been sbtained both in the laboratory and in the field.

\section{FORTHCOMING EVENTS}

\section{Tuesday, June 29}

Free German Institute of Scitence and Learning (at 16 Buckand Crescent, London, N.W.3), at 8 p.m.-Mr. J. A. Lauwerys : "Education in the U.S.A.".

Friday, July 2

Geologists' Association (at the Geological Society of London, GeoLoGists Associstilly, London, W.1), at 5.30 p.m.-Prof. O. T. Burlington House, "Piccadilly, London, w.1), at 5.30 p.m. .-A.".".

\section{Saturday, July 3}

NUTRITION SOCIETT (JOINT MEETING WITH THE FOOD GROUP OF NUTITION SOCIETY (JOINT MTRY) (at the London School of Hygiene and Tropical Medicine, Keppel Street, London, W.C.1), at 11 a.m.and Tropical Medicine, Keppel Street, London, W.C.1),

LONDON MATHEMATICAI SOCIETX (JOINT MEETING WITH THE LONDON BRANCH OF THE INSTITUTE OP PHYSICS) (at the Royal Society, Burlington House, Piccadilly, London, W.1), at 2 p.m.-Dr. A. C. Aitken, "F.R.S.: "Matrices in Practical Mathematics"' Dr. L. T. Comrie : "Computational Methods and Mathematical Tables": Mr. H. L. Blackburne: "Mathematical Solutions by Models"; Dr. S. Whitespecial reference to Circuit Theory".

\section{Saturday, July 3-Sunday, July 4}

Town and Codntry Planning Association (at the Waldorf Hotel, Aldwych, London, W.C.2), at 10.30 a.m.-- Conference on "Town Planning, Housing and Full Employment".

\section{APPOINTMENTS VACANT}

APPLICATIONs are invited for the following appointments on or before the dates mentioned

Assistant Master, able to offer Technical Drawing and/or Engineering Science and/or Practical Mathematics-The Headna
Junior Technical School, Millom, Cumberland (July 3).

Head of THE Mathematics and Physics Departirent in the

Rutherford Technical College-The Director of Education, Education Rutherford Technical College-The Director

Principal of the Barnsley Mining and Technical CollegeThe Director of Education, Education Department, Town Hall, Barnsley (July 7 )

Professor and Head of the Department of Electrical TechnotogY, and a PROFESSOR AND HEAD OF THE DEPARTMENT OF APPLIED
MECHANICS AND AUTOMOBILE ENGINERING-The Registrar, Indian Institute of Science, Bangalore, India (September 15).

Assistant Lecturer in Botany-The Principal, Swanley Horticultural College for Women, Swanley, Kent.

Agricultural ORGaNizer to the National Federation of Women's Institutes-The General Secretary, 39 Eccleston Street, London, S.W.1.

LEOTURER IN ENGINefring, for Achimota College, Gold CoastThe Ministry of Labour and National Service, Central (Technical and London, W.C.2.

\section{REPORTS and other PUBLICATIONS (not included in the monthly Books Supplement) Great Britain and Ireland}

Memoirs of the Cotton Research Station, Trinidad. Series B : Physiology, No.15: (1) On Diurnal Variations in the Mineral Content of the Leaf of the Cotton Plant, by $\mathrm{E}$. Phillis and T. G. Mason : (2) Studies on Foliar Hydration in the Cotton Plant (i) The Effects of Potassium Supply and Size of Plant (ii) Preliminary Observations using the Disc Culture Method, by T. G. Mason and E. Phillis ; (3) Studies on the Partition of the Mineral Elements in the Cotton Plant (iii) Mainly eoncerning Nitrogen, by E. Phillis and T. G. Mason. Pp. 437-486. (London: Empire Cotton Growing Corporation.) $28.6 d$. [175 Report of the Marlborough College Natural History Society for
the Year 1942. (No.91.) Pp. 24. (Marlborough: Marlborough College.) 28; to non-Members, 58 . The Limitations of Statistics in the Field of Public Opinion Research. By J. G. Ferraby. Pp. 25. (Manchester: Manchester Statistical
Society.) Education and Training for Engineers. Pp. ii +22 . (London: Institution of Electrical Engineers.) A Budgetary and Dietary Survey of Low Income Familes, Aberthe Children's Nutrition Council. Pp. 28. (Aberdeen: Aberdeen University Press.) $[205$

Royal Society for the Protection of Birds. Fifty-second Annual Report, January 1st to December 31 st, 1942 ; with Proceedings of Annual Meeting 1943. Pp. 48. (London: Royal Society for the Protection of Birds.) 18.
[245 Brompton Hospital Reports : a Collection of Papers recently pubBrompton Hospital Reports : a Collection of Papers recently pub-
lished from the Hospital. Vol. 11, 1942. Pp. vit 136. (London: lished from the Hospital. Vol. 11, 1942. Pp. vit 136. (London:
[245 Carnegie United Kingdom Trust. Twenty-ninth Annual Report, 942. Pp. 8. (Dunfermline : Carnegie United Kingdom Trust.) [245
Board of Education: Scottish Education Department. Youth Registration in 1942. (Cmd. 6446.) Pp. 28. (London: H.M. Stationery Office.) $6 d$. net. $[255$ Medical Research Council. War Memorandum No. 9: The Determination of Blood Groups. Pp. 20. (London: H.M. Stationery Office.)
[275 Empire Cotton Growing Corporation. Progress Reports from
Emet. Empire Cotton Growing Corporation. Progress Reports from Experiment Stations, Seasons 1941-1942 ; Programmes of Experiments, Season 1942-1943. Pp. il +183. (London: Empire Cotton
Growing Corporation.) 38.

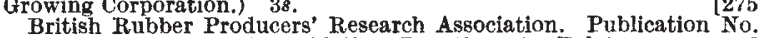
31: The Course of Autoxidation Reactions in Polyisoprenes and Allied Compounds, 4: The Isolation and Constitution of Photochemically-formed Methyl Oleate Peroxide; 5 : Observations on Fish-Oil Acids. By E. H. Farmer and D. A. Sutton. Pp. 8. Publication No. 32: The Course of Autoxidation Reactions in Polyisoprenes and Allied Compounds, 6: The Peroxidation of Rubber. By E. H. Farmer and A. Sundralingam. Pp. 9. (London: British Rubber $[275$
Producers' Research Association.)
Recommendations of the British X-Ray and Radium Protection Committee. Sixth Revised Report. Pp. 15. (Iondon: British X-Ray and Radium Protection Committee.)

\section{Other Countries}

Smithsonian Institution. War Background Studies, No. 10: Poisonous Reptiles of the World; a War-time Handbook. By Doris $\mathbf{M}$. Cochran. (Publication 3727.) Pp. $\mathrm{v}+37+17$ plates. (Washington, D.C.: Smithsonian Institution.) Smithsonian Miscellaneous Collections. Vol. 103, No. 10: A ReUnited States in Double Hale Solar Cycles, of Interest in Long-range Forecasting. By G. J. Kullmer. Pp. ii +20. (Washington, D.C.: Forecasting. By G. J. Kullmer. Pp. ii +20. (Washington, D.C.:
Smithsonian Institution.) Commonwealth of Australia : Council for Scientiflc and Industrial Research. Bulletin No. 151: The Control of St. John's Wort ( $\boldsymbol{H} y$ pericum perforatum L. var. augustifolium D.C.) by Competing Pasture pericum perforatum . var. augustifolium D.C.) by Competing Pasture
Plants. By R. M. Moore and A. B. Cashmore. Pp. $23+5$ plates. Bulletin No. 153: Pelagic Tunicates in the Plankton of Southeastern Australian Waters, and their Place in Oceanographic Studies. By Dr. Australian Waters, and their Place in Oceanographic Studies. By Dr. Harold Thompson; with a Statistical Analysis of Data on Total Plankton, by G. L. Kesteven. (Division of Fisheries, Report No. 8.) Pp. 56+1 plate. Bulletin No. 157: Studies in the Biology of Ausof the Biology of Mugil dobula Gunther. By G. L. Kesteven. (Division of thisheries, Report No. 9.) Pp. $147+2$ plates.' (Melbourne : Governof Fisheries, Report No. 9.) Pp. 147+2 plates. (Melbourne : Government Printer.)
Smithsonian Institution: United States National Museum. Bulletin Smithsonian Institution: United States National Museum. Bulletin
182: Monograph of the West Indian Beetles of the Family Staphylinidie. By Richard E. Blackwelder. Pp. viii + 658. (Washington, D.C. G. Government Printing Office.) 1 dollar.
U.S. Department of Agriculture. Miscellaneous Publication No. 401: Geographical Guide to Floras of the World ; an Annotated List with Special Reference to Useful Plants and Common Plant Names. Part 1: Africa, Australia, North America, South America, and Islands of the Atlantic, Pacific and Indian Oceans. By S. F. Blake and Alice C. Atwood. Pp. 336. (Washington, D.C.: Government Printing
Office) 75 cents. Office.) 75 cents.
Commonwealth of Australia : Council for Scientifle and Industrial Research. Bulletin No. 150: The Solls of the Parishes of Longford, Cressy, and Lawrence, County Westmorland, Tasmania. 1: A Soil Survey of the Area ; 2 : Pot Experiments with Subterranean Clover on the Cressy Shaley Clay-loam. By C. G. Stephens, J. G. Baldwin and J. S. Hosking. Pp. $40+6$ plates. Bulletin No. 155: Friction and Lubrication Report No. 2: The Lubricating Effect of Thin Metallic Films and the Theory of the Action of Bearing Metals. By Dr. F. P. Bowden and Dr. D. Tabor. Pp. $24+5$ plates. (Melbourne : Government Printer.)

[245

Public Library of South Australia. Annual Report of the Libraries Board of South Australia, July 1941 to June 1942. Pp. 6. (Adelaide
Public Library of South Australia.) Smithsonian Institution. War Background Studies, No. 11 : Egypt and the Suez Canal. By Frank H. H. Roberts, Jr. (Publication 3728.) Pp. iv $+68+25$ plates. (Washington, D.C. : Smithsonian InstituUniversity of Denver: Department of Anthropology. Archæological Series, Fourth Paper: Archeological Sites of the Cuchara Drainage, Southern Colorado. By Prof. E. B. Renaud and Janet Chatin. Pp. $62+4$ plates. (Denver, Colo: : University of Denver.) 75 cents. $[285$ Proceedings of the United States National Museum. Vol. 92, No. 3156: The Type Species of the Genera and Subgenera of Bees. By Grace A. Sandhouse. Pp. 519 620. (Washington, D.C. : Government 